\title{
Performance of macrophyte indicators to eutrophication pressure in ponds
}

Zhen Han, Baoshan Cui*

School of Environment, Beijing Normal University, State Key Joint Laboratory of Environmental Simulation and Pollution Control, Beijing 100875, China

\begin{abstract}
Aquatic macrophytes in ponds are considered as reliable indicators for detecting eutrophication pressure. In this study, the spatial distribution of total phosphorus (TP) and the ratio between transparency and water depth $\left(\mathrm{Z}_{\mathrm{SD}} / \mathrm{Z}_{\mathrm{M}}\right)$ were characterized in Lake Baiyangdian, north China. Total $\mathrm{P}$ and $\mathrm{Z}_{\mathrm{SD}} / \mathrm{Z}_{\mathrm{M}}$ were adopted to represent eutrophication pressure. The macrophyte indicators including richness of different species, diversity /evenness, biomass, and relative abundance for submerged/emergent ( $\left.\mathrm{RA}_{\text {sub/eme }}\right)$ and sensitive/tolerant submerged species $\left(\mathrm{RA}_{\text {sen/tol }}\right)$, were measured for each of the 38 ponds in the study area. Results showed that except richness of emergent and floating-leaved species, other macrophyte indicators were significantly correlated with $\mathrm{TP}$ and $\mathrm{Z}_{\mathrm{SD}} / \mathrm{Z}_{\mathrm{M}}$. Among them, evenness, biomass, $\mathrm{RA}_{\text {sub }} /$ eme and $\mathrm{RA}_{\text {sen }} /$ tol were selected to evaluate pond status because of their stronger response to TP. To evaluate the status for each pond, a scoring system was created by integrating TP and the four selected macrophyte indicators. We suggest that, control of external pollution sources and internal pollution sources, especially surface runoff from cropland reclamation and intensive use of fish feed from aquaculture, should be the focus of local managers. Inferred from the response of submerged species abundance to light availability, the value of $\mathrm{Z}_{\mathrm{SD}} / \mathrm{Z}_{\mathrm{M}}$ should be no less than 0.52 to restore submerged species in eutrophic ponds.
\end{abstract}

Keywords: Eutrophication pressure; Spatial distribution; Aquatic macrophyte; Relative abundance; Restoration.

\footnotetext{
${ }^{*}$ Corresponding author. Tel.: +86 10 58802079; Fax: +86 1058802079.

E-mail address: cuibs@bnu.edu.cn.
} 


\section{Introduction}

Aquatic macrophytes are considered as reliable indicators for detecting pond status because of their sensitive response to environmental stress, especially to eutrophication pressure (Mahaney et al., 2004; Sass et al., 2010). Under eutrophication pressure, macrophyte community composition shifts from a dominance of meadow-forming submerged species, to canopy-forming submerged, to floating-leaved, and eventually to emergent (Jeppesen et al., 2000; Egertson et al., 2004).

Submerged species are accepted as the most common indicators of eutrophication because they have been proven vulnerable to changes in water quality (Søndergaard et al., 2010). An increase in water turbidity with nutrient enrichment may directly result in changes in abundance, colonization depth limits, and community structure of submerged species (Cheruvelil and Soranno, 2008; Sass et al., 2010). In oligo-mesotrophic ponds, submerged species can stabilize sediments (Madsen et al., 2001), store nutrients (Dai et al., 2012), enhance water clarity (Søndergaard et al., 2010), and act as habitat for other aquatic organisms (e.g., zooplankton, fish, and invertebrates) (Jeppesen et al., 2000). However, an obvious reduction in abundance and richness of submerged species was often observed following water nutrient enrichment (Williams et al., 2004). This change was probably due to light attenuation and poor growth conditions (Gulati and Van Donk, 2002), and it could exert substantial and lasting effects on the biodiversity, structure, and function of pond ecosystems (Heino, 2002).

Compared with submerged species, the potential role of emergent ones in detecting eutrophication pressure remains uncertain. One point supported that emergent species are more sensitive to water-level fluctuations, shoreline modifications, and soil characteristics. For instance, Dudley et al. (2013) found that emergent species have significantly weaker relationships with total phosphorus (TP) than submerged species, but are more affected by spring flood-related water-level 
fluctuations. Differently, Alahuhta et al. (2013) and Kolada (2014) found that the percentage of emergent macrophyte in total littoral area is one of the most universal and best performing water quality indicators.

Qualitative indicators are more commonly adopted than quantitative ones for detecting eutrophication pressure. For instance, the presence of "clear/turbid water indicator species" is often used to detect nutrient level (Lauridsen et al., 2003; Jeppesen et al., 2007; Schneider, 2007). However, many species have a broad ecological range, and some that characterized as oligotrophic indicator species may also be present in meso-eutrophic water (Schneider, 2007), and species may also be differently classified when empirical relations are analyzed (Penning et al., 2008a). In addition, although a change from sensitive submerged species to tolerant ones is conceptually expected with increased eutrophication pressure, species occurrence is also likely determined by hydro-morphological variables and stochastic factors rather than eutrophication pressure, especially in shallow freshwater ecosystems (Moss, 2007). Compared with qualitative indicators, although quantitative indicators are being more well defined and more objective (e.g. percentage coverage of whole lake area, biomass, and frequency), they have been given less attention and are less commonly used for detecting eutrophication pressure (Cheruvelil and Soranno, 2008). In addition, many previous studies have focused on performance of individual indicator to eutrophication pressure (Egertson et al., 2004; del Pozo et al., 2011), however, using multiple macrophyte indicators instead of individual indicator seems to be more objective for detecting “ pressure-response ” relationship (Kolada, 2010).

The present study used Lake Baiyangdian as a case study, and the main objectives were to: (1) investigate spatial changes of eutrophication pressure indicators, (2) detect the performance of individual macrophyte indicator responding to eutrophication pressure, (3) evaluate pond status through applicable macrophyte indicators, and (4) summarize some implications for pond restoration. 


\section{Materials and Methods}

\subsection{Study area}

Lake Baiyangdian $\left(38^{\circ} 38^{\prime} \mathrm{N}, 115^{\circ} 54^{\prime} \mathrm{E}\right)$ is the largest macrophyte-dominated shallow lake in Baoding City, North China (Fig.1a). Before 1990s, the water level of Lake Baiyangdian was above $8.5 \mathrm{~m}$, and the lake was made up of 140 ponds that were interconnected through water channels. Nowadays, there are only less than 40 ponds exist due to continuously decreasing water input in the past few decades, and most of these ponds are isolated. Meanwhile, substantial species losses due to eutrophication result in different community compositions between study ponds (Fig.1b). With increasing awareness on pond restoration, eutrophication relief has been adopted as the main strategy by local managers. Therefore, objectively evaluating the status of different ponds is very necessary to ensure the efficiency of strategies for restoration. Fig.1. here.

\subsection{Data collection}

\subsubsection{Environmental variables}

We measured 10 water physicochemical variables monthly from June to September in 2012 in 38 ponds (Table 1). Water depth and Secchi depth transparency were measured within each ponds. We determined $\mathrm{pH}$ and dissolved oxygen (DO) using a portable multi-meter (YSI Pro Plus; YSI Incorporated, U. S. A). Water samples at the depth of $0.5 \mathrm{~m}$ were taken into 2-L polypropylene bottles, and preserved with ice in the field, and then kept at $4^{\circ} \mathrm{C}$ in the refrigerator when back to the lab. Total nitrogen (TN) and total phosphorus (TP) were measured using the cadmium reduction method and ascorbic acid method, respectively, after persulphate digestion in disposable polycarbonate bottles in an autoclave at $120{ }^{\circ} \mathrm{C}$ for 45 min (APHA, 1998). Suspend solids (SS) were collected with glass fiber filters (Whatman GFF; Whatman Incorporated, U.S.A.) under a low vacuum and dried before weighing. Chlorophyll a (Chl a) was determined spectrophotometrically after filtration on Whatman GF-C 
glass filters and $24 \mathrm{~h}$ extraction in $90 \%$ acetone (Lorenzen,1967).

We used digital land-use maps and a geographical information system (ArcGIS9.1; ESRI, Redlands, CA, U.S.A.) to obtain pond surface area, and the geographical coordinates $(x, y)$ of each pond center. The coordinates ' $x$ ' and ' $y$ ' were considered as spatial variables affecting eutrophication pressure, respectively. Spatial variables were rescaled from 0 to 1 using a max-min rescaling equation as follows:

$$
X_{i}^{\prime}=\frac{X_{i}-X_{\min }}{X_{\max }-X_{\min }}
$$

where $X_{i}$ is original value of longitude coordinate of a pond center, $X_{\min }$ and $X_{\max }$ represent the minimum and maximum values of longitude coordinates of the 38 pond centers, respectively, $X_{i}^{\prime}$ is the standardized value of $X_{i}$. The standardized value of latitude coordinate $Y_{i}$ were calculated with the same method.

\subsubsection{Macrophyte indicators}

The submerged, floating-leaved, and emergent macrophytes of all ponds were surveyed at the peak of growing season (August) in 2012. The occurrence of macrophytes throughout each pond was surveyed using a cruising boat and a rake. Macrophytes within each pond were sampled at eight sites to reasonably represent species composition. The location of sampled sites in each pond were mainly determined by its representativeness for community composition. At each site, four transects were placed perpendicular to shoreline and extending at a distance of $50 \mathrm{~m}$ from the shore. A $0.5 \mathrm{~m} \times 0.5 \mathrm{~m}$ quadrat was placed along each transection at $5 \mathrm{~m}$ intervals. Within each quadrat, the total number of species present were recorded to calculate species richness. The mean macrophyte coverage of each species was calculated as percentage of the total observed area. The aboveground biomass of macrophytes within each quadrat was collected by hand, and returned to the laboratory, and dried at $80{ }^{\circ} \mathrm{C}$ for $48 \mathrm{~h}$ to calculate their dry weight. Diversity level was calculated by Shannon-diversity index $H$ and evenness index $J$.

$$
H=-\sum_{i=1}^{N} \frac{n_{i}}{N} \ln \frac{n_{i}}{N}, J=\frac{H}{H_{\max }}, H_{\max }=\operatorname{Ln} S
$$

where $n_{i}$ is the proportion of the area inhabited by each macrophyte community in the 
total area of the phytolittoral, $N$ is the total area vegetated (100\%), $S$ is the species richness. $H_{\max }$ is the theoretical diversity index in a naturally non-disturbed pond (Ciecierska and Kolada, 2014).

Relative Abundance (RA) can represent community structure and changes of RA may considered as a tool for illustrating variations in community structure along eutrophication gradient (Stelzer et al.,2005; Penning et al., 2008b). RA of sensitive submerged species to tolerant ones was calculated by the following equation:

$$
R A_{\text {sen } / t o l}=\frac{\sum_{i=1}^{N_{s e n}} A_{i}-\sum_{j=1}^{N_{t o l}} A_{j}}{\sum_{k=1}^{N} A_{k}}
$$

where $N_{\text {sen }}$ is the number of sensitive species found in the pond, $N_{\text {tol }}$ is the number of tolerant species, $N$ is the total number of species, and $A$ is a measure of abundance. Sensitive and tolerant species were classified based on the method proposed by Penning et al. (2008a). This indicator produced a value between -1 and 1 for each pond, where 1 represents all species defined as sensitive, and -1 represents all species defined as tolerant. The sensitive submerged species mainly include Chara spp., Utricularia.vulgaris, Vallisneris.spiralis, and Hydrilla verticillata, while the tolerant submerged species mainly include Potamogeton.pectinatus, Potamogeton.maackianus, Potamogeton.malaianus, Myriophyllum.verticillatum, and Ceratophyllum.demersum.

RA of submerged species to emergent ones was also calculated by the same equation. The subscript $N_{s e n}$ and $N_{t o l}$ in above equation were replaced by $N_{s u b}$ and $N_{e m e}$, respectively, where $N_{\text {sub }}$ is the number of submerged species found in the pond, $N_{\text {eme }}$ is the number of emergent species, $N$ is the total number of species, and $A$ is a measure of abundance. This indicator also produced a value between -1 and 1 for each pond, where 1 represents all species defined as submerged, and -1 represents all species defined as emergent. The dominant emergent species in study area were Nelumbo.nucifera, Phragmites.australis, and Typha.angustifolia.

\subsection{Statistical analysis}

Pearson correlation analysis was conducted to analyze the relationships among TP, 
$\mathrm{Z}_{\mathrm{SD}} / \mathrm{Z}_{\mathrm{M}}$ and other environmental variables.

Regression analysis was adopted to analyze relationships between spatial variable, macrophyte indicators, and the two eutrophication indicators ( $\mathrm{TP}$ and $\left.\mathrm{Z}_{\mathrm{SD}} / \mathrm{Z}_{\mathrm{M}}\right)$. We further divided TP gradient into five classes: $<0.05,0.05-0.1,0.1-0.2,0.2-0.4$, and 0.4-0.6 mg/L and then explored changes of macrophyte indicators among different TP classes. The macrophyte indicators that strongly responded to eutrophication pressure were selected as applicable indicators for evaluating pond status. Their values were classified into five numerical intervals according to TP classes, then were standardized with scores from 1 to 5 , respectively. Total score representing pond status was calculated by summed scores of different applicable macrophyte indicators, and it was subsequently be used for pond categorization, specifically, total score $<4$ : status I, Excellent status; total score 5-8: status II, Good status; total score 9-12: status III, Moderate status; total score 13-16: status IV, Poor status; total score 17-20: status V, Bad status.

The Pearson correlation analysis and regression analysis were conducted using Origin version 8.0, and the spatial analysis of $\mathrm{TP}$ and $\mathrm{Z}_{\mathrm{SD}} / \mathrm{Z}_{\mathrm{M}}$ were carried out using Surfer version 8.0.

\section{Results}

\subsection{Environmental background}

The studied physiochemical variables largely varied among study ponds (Table 1). Among physical factors tested, pond area and mean depth showed a significant positive but very weak inter correlation $(\mathrm{r}=0.33, \mathrm{P}<0.01$, Table 2$)$.

$\mathrm{TP}$ and $\mathrm{Z}_{\mathrm{SD}} / \mathrm{Z}_{\mathrm{M}}$ were significantly correlated with 6 and 4 variables, respectively. Water depth was the best explanatory variable of TP concentration ( $\mathrm{r}=-0.71, \mathrm{P}<0.001$, Table 2), whereas effects of pond size on TP concentration were much weaker $(r=0.03$, $\mathrm{P}>0.05$, Table 2). Thus deeper ponds have slightly less phosphorus than shallow ones.

The correlation between $\mathrm{pH}$ and $\mathrm{Z}_{\mathrm{SD}} / \mathrm{Z}_{\mathrm{M}}$, although significant, were relatively 
weaker ( $\mathrm{r}=0.35, \mathrm{P}<0.05$, Table 3). Although Chl-a and $\mathrm{NH}_{3}-\mathrm{N}$ were found to be highly related with $\mathrm{Z}_{\mathrm{SD}} / \mathrm{Z}_{\mathrm{M}}(\mathrm{r}=-0.57$ and -0.42 , respectively, Table 2$)$, the two variables were more affected by TP ( $\mathrm{r}=0.63$ and 0.58 , respectively, Table 2$)$.

We found that the spatial changes of $\mathrm{TP}$ and $\mathrm{Z}_{\mathrm{SD}} / \mathrm{Z}_{\mathrm{M}}$ were mainly determined by pond locations. TP concentration was geographically structured, the majority of high values of TP concentration were found in ponds located in the west and north of the study area, and some high values of TP concentrations were found in ponds in the middle of study area (Fig.2a). Meanwhile, high $\mathrm{Z}_{\mathrm{SD}} / \mathrm{Z}_{\mathrm{M}}$ values were more evenly distributed in ponds located in the east and south of the study area (Fig.2b). The response curves and correlations between the two eutrophication indicators and spatial variables varied (Fig.3). Specifically, longitude coordinates explained more variations of the two indicators than that of latitude coordinates, and correlations between TP concentration and latitude coordinates were insignificant. Overall, linear regression analysis demonstrated that eutrophication pressure was strongly affected by spatial variables and showed an obvious decrease from west to east. The only exception is that ponds located in middle of the study area also had high nutrient levels.

Table 1 here.

Table 2 here.

Fig.2. here.

Fig.3. here.

\subsection{Response of macrophyte indicators to eutrophication pressure}

As shown in Table 3, the significance and strength of relationships between eutrophication-pressure indicators and macrophyte indicators substantially varied.

Richness of emergent, floating-leaved were not significantly related with TP and $\mathrm{Z}_{\mathrm{SD}} / \mathrm{Z}_{\mathrm{M}}$. Richness of submerged and total species were not significantly correlated with TP $(\mathrm{P}>0.05)$, whereas they were significantly correlated with $\mathrm{Z}_{\mathrm{SD}} / \mathrm{Z}_{\mathrm{M}}(\mathrm{r}=0.45$ and 0.37, respectively, Table 3). No significant relationships were found between richness of emergent and floating-leaved species and the two eutrophication pressure 
indicators (Table 3). Both Shannon-Weiner index $H$ and evenness index $J$ showed significant relationships with $\mathrm{TP}$ and $\mathrm{Z}_{\mathrm{SD}} / \mathrm{Z}_{\mathrm{M}}$ (Table 3). RA sub/eme and RA sen/tol were found to be strongly related with the two pressure indicators (Table 3).

We further fitted response curves between sensitive macrophyte indicators and eutrophication pressure indicators. As shown in Fig.4, species richness was highest in meso-trophic ponds and did not show a clear (linear/log linear) negative response to eutrophication. Fig.5 showed that both $J$ and $H$ were logarithmically and linearly related with $\mathrm{TP}$ and $\mathrm{Z}_{\mathrm{SD}} / \mathrm{Z}_{\mathrm{M}}$, respectively. Considering the correlations, $J$ performed better than $H$. RA sub/eme and RA sen/tol showed similar trends as $H$ and $J$ to the two eutrophication pressure indicators (Fig.6). Total biomass was positively correlated with nutrient enrichment and negatively related with $\mathrm{Z}_{\mathrm{SD}} / \mathrm{Z}_{\mathrm{M}}$ (Fig.7a,b). The responses of total coverage to $\mathrm{TP}$ and $\mathrm{Z}_{\mathrm{SD}} / \mathrm{Z}_{\mathrm{M}}$ showed an opposite trend with biomass (Fig.7).

A total phosphorus (TP) gradient can be divided into five TP classes (class 1-5: $<0.05,0.05-0.1,0.1-0.2,0.2-0.4,>0.4 \mathrm{mg} / \mathrm{L})$. Both submerged richness and total richness showed unimodal trend along TP gradient, and obvious decreases from class 3 to 5 after initial increases from class 1 to 3 were found for the two indicators (Fig.8a). Both $H$ and $J$ decreased along TP gradient. For $H$, obvious decreases mainly occurred from class 1 to 2 , and class 4 to 5 , while the largest reduction for $J$ occurred from class 2 to class 3 (Fig. 8 b). Total biomass showed stable increases along TP gradient, while total coverage showed gradual decreases along TP gradient (Fig.8c). Both RA sen/tol and RA sub/eme showed decreasing trend along TP gradient, and the decreasing amplitude was similar between different TP classes (Fig.8d).

Table 3 here.

Fig.4. here.

Fig.5. here.

Fig.6. here.

Fig.7. here.

Fig.8. here. 


\subsection{Pond status}

The evenness, biomass, as well as RA sub/eme and RA sen/tol were eventually selected to evaluate pond status. Numerical intervals of the four indicators responding to each TP class were listed and were standardized with scores from 1 to 5 , respectively (Table 4). According to their total scores, all ponds were classified into five categories (Table 5). Specifically, ponds with excellent status and good status were mainly located in east and south of the study area, while ponds with bad status and poor status were mainly located in northwest and southwest of study area. Besides, most of ponds with moderate status were located in north of study area.

Table 4 here.

Table 5 here.

\section{Discussion}

\subsection{Eutrophication pressure}

Total phosphorus, total nitrogen, transparency and Chl-a are the most commonly used indicators to represent eutrophication pressure by many scholars (Jeppesen et al., 2000; Kolada, 2010; Søndergaard et al., 2010). In this study, we adopted TP and $\mathrm{Z}_{\mathrm{SD}} / \mathrm{Z}_{\mathrm{M}}$ as indicators of eutrophication pressure, which were different from indicators used in previous studies to some extent. Adoption of the two indicators can be explained as follows. Phosphorus is traditionally regarded as the main eutrophication stressor in freshwater ecosystems, and inter-correlation analysis also showed that most environmental variables were significantly correlated with TP (Table 2 ). $\mathrm{Z}_{\mathrm{SD}} / \mathrm{Z}_{\mathrm{M}}$ is defined as the ratio between water transparency $\left(\mathrm{Z}_{\mathrm{SD}}\right)$ and mean water depth $\left(\mathrm{Z}_{\mathrm{M}}\right)$, and it can be used to represent the combination effect of light availability and water depth (Hakanson and Boulion, 2002). Biologically, larger value of $\mathrm{Z}_{\mathrm{SD}} / \mathrm{Z}_{\mathrm{M}}$ mean aquatic habitat is more suitable for photosynthesis, and the relationship between $\mathrm{Z}_{\mathrm{SD}} / \mathrm{Z}_{\mathrm{M}}$ and macrophyte abundance indicate cleaner and shallower aquatic habitat 
have more abundant macrophyte (Wang et al., 2005). Although transparency was more commonly used to represent light availability that determines macrophyte growth, biological meaning of $\mathrm{Z}_{\mathrm{SD}} / \mathrm{Z}_{\mathrm{M}}$ is more objective (Liang et al., 1995; Squires et al., 2002). The results showed that Chl-a was significantly related with TP and transparency $(\mathrm{r}=0.58, \mathrm{P}<0.01 ; \mathrm{r}=-0.75, \mathrm{P}<0.001$, respectively, Table 2$)$, however, it wasn't selected as the major eutrophication pressure indicators for several reasons. Firstly, high Chl-a concentration is considered as the consequence of nutrient enrichment, while high TP concentration is the fundamental cause for eutrophication pressure (Penning et al., 2008a, 2008b; Kolada, 2014). Besides, the significant relationship between Chl-a and light availability may also affected by water level of study area. As previously reported by del Pozo et al. (2010), ponds could maintain macrophyte growth at high Chl-a concentration because of water level decrease and higher light availability.

We also found that eutrophication pressure was strongly geographically structured in the study area, and a decrease in eutrophication gradient from west to east was revealed (Fig.2). This phenomenon was probably due to the location of external pollution sources inlet and the topographic features of study area. The primary regular recharge water source for study area, is Fuhe river, which bears the majority of domestic wastewater from Baoding City (Tian et al., 1995). Fuhe river, enters study area from the west, thereby resulting in high nutrient levels in west ponds (Fig.1b). Although terrain of study area was relatively flat, elevation of the northwest region was higher. Thus most ponds in this region have dried up due to continuous decreasing water level, thereby creating conditions for agricultural reclamation. Abundant nutrient from agricultural surface runoff may result in bad status of the ponds located in this region (Ponds 34, 35, 36, 37, 38, Fig.1b). The only exception is the ponds located in the middle of study area, especially that around Quantou Town, which are also characterized by high nutrient level. We consider that enclosure aquaculture development from 1990s may directly result in this phenomenon. The total nitrogen and total phosphorus concentrations in fish feed were $3.29 \%$ and $0.502 \%$, respectively, so intensive use of fish feed in ponds may enhance nutrient 
level (Chen et al., 2010).

\subsection{Response of macrophyte indicators to eutrophication pressure}

Species richness

In the present study, no significant relationships existed between richness of emergent and floating-leaved and TP concentration (Table 3). This phenomenon may be explained as emergent and floating-leaved species can extend their culms or leaves above or on the water surface, and hence they do not restrict by light attenuation with nutrient concentration (Radomski and Goeman, 2001; Alexander et al., 2008). Submerged richness and total richness showed a unimodal trend with nutrient concentration, with the highest number of species found in mesotrophic ponds, and the lowest in oligotrophic and hypertrophic ponds (Fig.4a, c), thereby indicating that richness was not a suitable indicator for evaluating pond status. This finding is supported by studies of Penning et al. (2008b) that besides nutrient level, species richness is also determined by morphological variables, such as surface area and shoreline development (Jennings et al., 2003; Karus and Feldmann, 2013).The higher submerged richness in mesotrophic ponds compared with eutrophic ponds may be supported by the presence of many tolerant species, such as Potamogeton spp. (e.g., $P$. pectinatus, P. maackianus, $P$. malaianus), Myriophyllum. spicatum, and Ceratophyllum. demersum. The specific adaption strategies of these species allow them to survive high turbidity. For instance, $P$. pectinatus can elongate its shoots and form a canopy in the upper water layer (Bakker et al., 2010), whereas C. demersum is often characterized as a rootless species living just below water surface (Egertson et al., 2004; Alexander et al., 2008; Dai et al., 2012). Thus, these species are not restricted by poor light availability. However, in poly- and hyper-eutrophic ponds, even these species would not exist because of the dominance of phytoplankton. In contrast to our findings, Kosten et al. (2009) and Søndergaard et al. (2010) found monotonic negative relationships between richness and nutrient concentrations. The differences between previous results and those of this study were probably caused by paucity or even absence of oligotrophic lakes in the previous studies. Submerged 
richness contribute to more than half of the total richness in ponds, thereby resulting the significant relationship between total richness and the two eutrophication indicators.

\section{Diversity}

Both Shannon diversity index $(H)$ and Evenness index $(J)$ were significantly related to TP and $\mathrm{Z}_{\mathrm{SD}} / \mathrm{Z}_{\mathrm{M}}$ (Fig.5). As for the "pressure-response" curve, both $H$ and $J$ were logarithmically and negatively correlated with TP, but were linearly and positively correlated with $\mathrm{Z}_{\mathrm{SD}} / \mathrm{Z}_{\mathrm{M}}$. In this study, we eventually adopted $J$ rather than $H$ to represent diversity in the subsequent analysis because $J$ can represent simplification of macrophyte communities resulting from eutrophic pressure (Ciecierska, 2006; Ciecierska and Kolada, 2014). In non-disturbed ponds (Pond 6,7,8,9,13,14,15,16), $H$ may reach $H_{\max }$ during natural succession, thus the value of evenness $J$ is approximately to 1 . In ponds affected by eutrophic pressure, macrophyte communities are simplified; some species are lost or even disappear, whereas others become prevalent or even dominant, resulting in the decrease of $J$ values $\left(J=H / H_{\max }\right)$. Besides,

calculation method of $J$ can eliminate the effects of species richness $(J=H / L n S)$, whereas $H$ is strongly affected by the number of species.

\section{Total coverage and biomass}

Abundance of aquatic macrophyte is usually expressed as macrophyte coverage, biomass, or maximum colonization depth. The total coverage, is often expressed by absolute units or in terms of the percentage of pond area (Kolada, 2010). Therefore, total coverage might be relatively unreliable, as it is determined by hydro-morphological variables rather than nutrient concentration. The late summer macrophyte biomass may reflect primary production of the whole growing period, and its value is more stable than coverage. Fitted curves also showed that biomass was strong and significantly related with $\mathrm{TP}$ and $\mathrm{Z}_{\mathrm{SD}} / \mathrm{Z}_{\mathrm{M}}$ (Fig.7c,d). Therefore, we eventually adopted biomass as a reliable indicator.

Changes in total coverage and biomass were fundamentally due to replacement 
of the submerged species with the emergent species. With light attenuation along eutrophication gradient, substantial losses and even disappearances may occur for submerged species, directly cause reduction in coverage (Søndergaard et al., 2010). Increased biomass may be attributed to excessive growth and proliferation of emergent species, especially P.australis. P.australis is the dominant emergent species in study area, shallow water depth in study ponds and developed rhizomes of $P$. australis allow it to proliferate and out-compete other emergent species for abiotic factors. Considering its great capacity for absorbing nutrients in its tissues, P. australis often accumulates large biomass in eutrophic ponds (Karunaratne et al., 2003, 2004). Proliferation of $P$. australis may also promote re-colonization of Chara, which can form a dense meadow that accumulates a relatively larger biomass than that achieved by canopy-like growth forms and rootless submerged species (Bakker et al., 2010), then result in a slight increase in total biomass.

\section{Community structure}

Both $\mathrm{RA}_{\text {sen/tol }}$ and $\mathrm{RA}_{\text {sub/eme }}$ were significantly correlated with the two eutrophication indicators. Logarithmically linear and linearly fitted curves were observed for TP and $\mathrm{Z}_{\mathrm{SD}} / \mathrm{Z}_{\mathrm{M}}$, respectively (Fig.6). Thus we regarded relative abundance as a reliable indicator of eutrophication pressure.

Some scholars regarded the absence/presence of tolerant or sensitive species as important indicators of ecological status (Penning et al., 2008a; Sand-Jensen et al., 2008). Although species sensitivity or tolerance may possibly be defined by only their occurrence along a phosphorus gradient, most of the species may occur in waters with a wide nutrient range for long-term adaptation. For instance, although Chara is known to occur mainly in oligotrophic waters, they can appear over a broad range of nutrient concentrations, even in ponds with higher nutrient levels ( $\mathrm{TP}>0.75 \mathrm{mg} / \mathrm{L}$ ), thereby indicating its wide range of nutrient requirement and its limited ability for evaluating nutrient status. Similarly, high heterogeneity of Potamegeton spp in terms of their nutrient requirements may also interfere with "pressure-response" relationship. Therefore, only the presence/absence of some species could not reflect changes in 
community structure with eutrophication pressure. It is noted that Chara still occur in ponds with high nutrient level. Except for wide range of nutrient requirement, this phenomenon would also be explained by two reasons. First, although light availability was weakened by high nutrient level, shallow water depth still ensure favorable light availability for Chara growth. Second, the dense bed formed by P.australis can relieve disturbance from wave erosion, zoobenthos, and fish, and inhibit phytoplankton through allelopathy; then, these dense beds act as refuge areas for the growth of Chara (Egertson et al., 2004).

The response curve of $\mathrm{RA}_{\text {sen/tol }}$ indicated that loss of sensitive species (e.g., Chara) is counterbalanced by the increase of tolerant ones (e.g., Potamegeton spp.) along eutrophication gradient. In oligotrophic ponds, Chara is believed to play an important role in regulating water quality, dense Chara meadows have a strong positive effect on water transparency, and they stabilize clear water state by inhibiting phytoplankton (via allelopathy) and restraining sediment re-suspension and erosion (Hilt et al., 2006; Gulati et al., 2008). As nutrient enrichment, water turbidity increases due to excessive growth of phytoplankton. Chara would no longer exist in large stands and is gradually replaced by Potamegeton spp.

The $\mathrm{RA}_{\text {sub/eme }}$ were also significantly affected by eutrophication pressure. In non-disturbed ponds (Pond 6,7,8,9,13,14,15,16), both submerged and emergent are usually abundantly developed, but nutrient enrichment process in the water column restricts growth of the submerged via decreased light availability. However, this process does not affect emergent growth, because emergent species can extend their leaves or culms above the water surface.

The inclusion of emergent species in the detection of "pressure-response" relationship is a controversial issue. Some scholars pointed out that emergent species often colonize the inshore zone of the littoral, and are considered to respond more sensitively to soil texture, water level, and human activity (e.g. harvesting), rather than nutrient enrichment in water column (del Pozo et al., 2010; Hicks and Frost, 2011). From responses of $\mathrm{RA}_{\text {sub/eme }}$ to the $\mathrm{TP}$ and $\mathrm{Z}_{\mathrm{SD}} / \mathrm{Z}_{\mathrm{M}}$ (Fig.6a), we may infer that increases of emergent were significantly and strongly correlated with eutrophication 
pressure. This results are consistent with those obtained in previous studies of Kolada (2010), and Søndergaard et al. (2010, 2013), and it can be explained as follows. First, harvesting for emergent is mainly conducted on raised field (A raised field was constructed by local farmers with pond sediment and planted with Phragmites australis for economic value, $1.0 \mathrm{~m}$ to $1.5 \mathrm{~m}$ higher than the water surface) rather than in water in the study area. Besides, considering the study area's gentle slope and low water level, most of the surface area, or even the entire pond bottom would be suitable for emergent growth, and sufficient nutrient may also promotes its biomass accumulation and proliferation.

In all the ponds analyzed in this study, significant relationships were rarely found between eutrophication pressure indicators and floating-leaved species. Neither species richness nor abundance of floating-leaved species was significantly respond to eutrophication pressure. This phenomenon might have resulted from the high tolerance of floating-leaved species to increased water turbidity (del Pozo et al., 2011). Besides, both abundance and richness of floating-leaved species were relatively smaller than those of emergent and submerged species, thereby leading to the insignificant role of floating-leaved species.

We eventually adopted multiple indicators, including evenness, biomass, and relative abundance, to evaluate pond status, because individual indicator does not necessarily correctly represent ecological responses to disturbances. Moreover, the use of multiple indicators has also been suggested by various studies (Penning et al., 2008b; del Pozo et al., 2010; Kolada, 2010). Among these indicators, evenness expresses the simplification of community composition resulting from eutrophication pressure. Biomass represents primary production of macrophyte community. Relative abundance can be considered as the quantification of the replacement of sensitive species with tolerant species, as well as the replacement of submerged with emergent species.

An obvious change in aquatic macrophytes along eutrophication gradient can be summarized as follows: sensitive submerged species (Chara spp.) -- tolerant submerged species (Potagemeton spp.) -- emergent. With light attenuation, sensitive 
submerged species are gradually replaced by tolerant ones, thereby leading to the disappearance of submerged macrophytes, and the domination of emergent macrophytes. Moreover, these changes can be classified into five different categories according to the boundary values of macrophyte indicators. In status I, few submerged species were observed in oligotrophic ponds. In status II, the dominant sensitive species Chara may accumulate large biomass by taking up a sufficient amount of nutrient with increasing TP concentration. In status III, subsequent increases of nutrient would weaken light availability and result in the occurrence of tolerant species, such as Potagemeton spp. Then the sensitive species were gradually replaced by the tolerant ones, and species losses and simplification of community composition are observed in status IV. In the status V, high turbidity in hyper-eutrophic ponds would eventually result in the substantial losses or even disappearance of submerged macrophytes, and dominance of the emergent species.

Changes of macrophyte indicators may not proceed linearly across the eutrophication gradient. In situation when the transparency drops below the threshold, , a clear-water state dominated by submerged macrophytes can also shift rapidly to a turbid-water state, without any transitional state in between (Scheffer, 1998), and emergent growth would also be suppressed if high water level occurs simultaneously. This phenomenon was observed in Pond 36 (Fig.1b), in which both submerged and emergent abundance are very low in hyper-eutrophic and deep water areas.

\subsection{Management implications}

Based on spatial distribution of eutrophication pressure and performances of macrophyte indicators, we suggest some implications for pond restoration. First, the control of external pollution sources should be considered for pond restoration. It is reported that the discharge of domestic waste water from Fuhe river into study area reportedly amounted to $32.5 \times 10^{4} \mathrm{~m}^{3} / \mathrm{d}$, thereby producing enormous pressure on the whole ecosystem (Cui et al., 1999). Thus, it is critical to construct a wastewater 
treatment facility in the inlets of the study area. Second, internal pollution sources within the study area, including cropland reclamation and enclosure aquaculture development, should be the focus of local managers. Cropland reclamation mainly occurs in long-term drought ponds in the northwest of the study area, whereas intensive enclosure aquaculture mainly occurs in middle of study area, especially in ponds around Quantou Town. We assume that the fundamental restoration measure for ponds located in the northwest of the study area is to form a sustainable artificial water replenishment mechanism, so that water can be restored in drought ponds, which in turn would serve as suitable habitats for macrophytes. Meanwhile, organic feed is recommended for aquaculture to decrease nutrient loading in this area. Finally, response curve of $\mathrm{RA}_{\text {sub/eme }}$ to $\mathrm{Z}_{\mathrm{SD}} / \mathrm{Z}_{\mathrm{M}}$ may provide the basis for determining the amplitude of water level regulation, which is an essential factor affecting restoration efficiency of submerged species in eutrophic ponds (Hilt et al., 2006; Gulati et al., 2008). From Fig.6b we can infer that $\mathrm{RA}_{\text {sub }} / \mathrm{RA}_{\mathrm{eme}}$ values of most study ponds were below zero when $\mathrm{Z}_{\mathrm{SD}} / \mathrm{Z}_{\mathrm{M}}$ value was less than 0.52 , indicating dominance of emergent species in these ponds. Conversely, $R_{\text {sub }} / R_{\text {eme }}$ values of most study ponds were larger than zero when $\mathrm{Z}_{\mathrm{SD}} / \mathrm{Z}_{\mathrm{M}}$ value was larger than 0.52 , indicating the dominance of submerged species in these ponds. Therefore, we regard ' 0.52 ' as the threshold that distinguish whether submerged species is dominance in ponds, and this value can be used for guiding restoration of submerged species through water level regulation.

\section{Conclusion}

In this study, we evaluated the performances of different macrophyte indicators to eutrophication pressure in ponds. Results showed that both $\mathrm{TP}$ and $\mathrm{Z}_{\mathrm{SD}} / \mathrm{Z}_{\mathrm{M}}$ were geographically structured, and a decreasing eutrophication pressure from west to east was also revealed. Except for richness of emergent species and floating-leaved species, other macrophyte indicators were significantly correlated with $\mathrm{TP}$ and $\mathrm{Z}_{\mathrm{SD}} / \mathrm{Z}_{\mathrm{M}}$. We 
eventually adopted evenness, biomass, as well as $\mathrm{RA}_{\text {sub/eme }}$ and $\mathrm{RA}_{\text {sen/tol }}$ as applicable indicators for evaluating pond status. The total score representing pond status was subsequently calculated based on standardized value of the four applicable indicators, from which all ponds were classified into five categories. Overall, our results suggested that controlling external and internal pollution sources simultaneously should be the focus of local managers. Besides, we regard ' 0.52 ' as $\mathrm{Z}_{\mathrm{SD}} / \mathrm{Z}_{\mathrm{M}}$ threshold that can be used to determine the water level regulation for restoring submerged species in eutrophic ponds.

\section{Acknowledgements}

This research was funded by China National Funds for Distinguished Young Scientists (51125035), National Science Foundation for Innovative Research Group (51121003), and Major Science and Technology Program for Water Pollution Control and Treatment (2009ZX07209-008).

\section{References}

Alahuhta, J., Kanninen, A., Hellsten, S., Vuori, K.-M., Kuoppala, M., Hämäläinen, H., 2013. Environmental and spatial correlates of community composition, richness and status of boreal lake macrophytes. Ecol. Indic. 32, 172-181.

Alexander, M.L., Woodford, M.P., Hotchkiss, S.C., 2008. Freshwater macrophyte communities in lakes of variable landscape position and development in northern Wisconsin, U.S.A. Aquat.Bot. 88, 77-86.

APHA, 1998. Standard Methods for the Examination of Water and Wastewater, 20th edn. American Public Health Association, Washington.

Bakker, E.S., Van Donk, E., Declerck, S.A.J., Helmsing, N.R., Hidding, B., Nolet, B.A., 2010. Effect of macrophyte community composition and nutrient enrichment on plant biomass and algal blooms. Basic.Appl.Ecol. 11, 432-439.

Chen, X.Y., Tian, Z.F., Xiao, G.H., Hu, X.B., Bian, W., 2010. Analysis on the Eutrophication Evaluation of Baiyangdian Aquaculture Water. Hebei Fisheries. 5, 41-44. (in Chinese) 
Cheruvelil, K.S., Soranno, P.A., 2008. Relationships between lake macrophyte cover and lake and landscape features. Aquat.Bot. 88, 219-227.

Ciecierska, H., 2006. Evaluation of the status of lakes located in the City of Olsztyn (Masurian Lake District, N-E Poland) by the macrophytoindication method (MPhI). Hydrobiologia. 570, $141-146$.

Ciecierska, H., Kolada, A., 2014. ESMI: a macrophyte index for assessing the ecological status of lakes. Environ.Monit.Assess. 186, 5501-5517.

Cui, X. L., Hou, Y.Q., Wang, J., 1999. The opinion on the ecological environment protection of Baiyangdian Lake. Journal of Baoding Teachers College. 12, 86-89. (in Chinese)

Dai, Y., Jia, C., Liang, W., Hu, S., Wu, Z., 2012. Effects of the submerged macrophyte Ceratophyllum demersum L. on restoration of a eutrophic waterbody and its optimal coverage. Ecol.Eng. 40, 113-116.

del Pozo, R., Fernández-Aláez, C., Fernández-Aláez, M., 2010. An assessment of macrophyte community metrics in the determination of the ecological condition and total phosphorus concentration of Mediterranean ponds. Aquat.Bot. 92, 55-62.

del Pozo, R., Fernández-Aláez, C., Fernández-Aláez, M., 2011. The relative importance of natural and anthropogenic effects on community composition of aquatic macrophytes in Mediterranean ponds. Mar. Freshwater.Res. 62, 101-109.

Dudley, B., Dunbar, M., Penning, E., Kolada, A., Hellsten, S., Oggioni, A., Bertrin, V., Ecke, F., Søndergaard, M., 2013. Measurements of uncertainty in macrophyte metrics used to assess European lake water quality. Hydrobiologia. 704, 179-191.

Egertson, C., Kopaska, J., Downing, J., 2004. A century of change in macrophyte abundance and composition in response to agricultural eutrophication. Hydrobiologia. 524, 145-156.

Gulati, R., van Donk, E., 2002. Lakes in the Netherlands, their origin, eutrophication and restoration: state-of-the-art review. Hydrobiologia. 478, 73-106.

Gulati, R.D., Dionisio Pires, L.M., Van Donk, E., 2008. Lake restoration studies: Failures, bottlenecks and prospects of new ecotechnological measures. Limnologica - Ecology and Management of Inland Waters. Aquat.Bot. 38, 233-247.

Hakanson, L., Boulion, V.V., 2002. Empirical and dynamical models to predict the cover, biomass and production of macrophytes in lakes. Ecol. Model. 151, 213-243. 
Heino, J., 2002. Concordance of species richness patterns among multiple freshwater taxa: a regional perspective. Biodivers. Conserv. 11, 137-147.

Hicks, A.L., Frost, P.C., 2011. Shifts in aquatic macrophyte abundance and community composition in cottage developed lakes of the Canadian Shield. Aquat. Bot. 94, 9-16.

Hilt, S., Gross, E.M., Hupfer, M., Morscheid, H., Mählmann, J., Melzer, A., Poltz, J., Sandrock, S., Scharf, E.-M., Schneider, S., van de Weyer, K., 2006. Restoration of submerged vegetation in shallow eutrophic lakes - A guideline and state of the art in Germany. Limnologica - Ecology and Management of Inland Waters. 36, 155-171.

Jennings, M.J., Emmons, E.E., Hatzenbeler, G.R., Edwards, C., Bozek, M.A., 2003. Is littoral habitat affected by residential development and land use in watersheds of Wisconsin lakes? Lake.Reserv.Manage. 19, 272-279.

Jeppesen, E., Peder Jensen, J., Søndergaard, M., Lauridsen, T., Landkildehus, F., 2000. Trophic structure, species richness and biodiversity in Danish lakes: changes along a phosphorus gradient. Freshwater Biol. 45, 201-218.

Jeppesen, E., Søndergaard, M., Meerhoff, M., Lauridsen,T.L., Jensen, J.P., 2007. Shallow lake restoration bynutrient loading reduction - some recent findings and challenges ahead. Hydrobiologia. 584, 239-252.

Karunaratne, S., Asaeda, T., Yutani, K., 2003. Growth performance of Phragmites australis in Japan: influence of geographic gradient. Environ.Exp. Bot. 50, 51-66.

Karunaratne, S., Asaeda, T., Yutani, K., 2004. Shoot regrowth and age-specific rhizome storage dynamics of Phragmites australis subjected to summer harvesting. Ecol. Eng. 22, 99-111.

Karus, K., Feldmann, T., 2013. Factors influencing macrophyte metrics in Estonian coastal lakes in the light of ecological status assessment. Hydrobiologia. 704, 153-163.

Kolada, A., 2010. The use of aquatic vegetation in lake assessment: testing the sensitivity of macrophyte metrics to anthropogenic pressures and water quality. Hydrobiologia. 656, 133-147.

Kolada, A., 2014. The effect of lake morphology on aquatic vegetation development and changes under the influence of eutrophication. Ecol. Indic. 38, 282-293.

Kosten, S., Kamarainen, A.M.Y., Jeppesen, E.,Van Nes, E.H., Peeters, E.T.H.M., Mazzeo, N., Sass, L., Hauxwell, J., Hansel-Welch, N., Lauridsen, T.L., Søndergaard, M., Bachmann, R.W., 
Lacerot, G., Scheffer, M., 2009. Climate-related differences in the dominance of submerged macrophytes in shallow lakes. Global.Change.Biol. 15, 2503-2517.

Lauridsen, T.L., Jensen, J.P., Jeppesen, E., Søndergaard, M., 2003. Response of submerged macrophytes in Danish lakes to nutrient loading reductions and biomanipulation. Hydrobiologia.506, 641-649.

Liang, Y.L., Cai, Q.H., Su, Z.G., 1995. Dynamics of aquatic macrophytes and their relationship with some environmental factors of Baoan Lake, Hubei. In: Liang, Y.L., Liu, H.Q. (Eds.), Resources, Environment and Fishery Ecological Management of Macrophytic Lakes. Science Press, Beijing, pp. 172-177 (in Chinese).

Lorenzen, C.J., 1967. Determination of chlorophyll and Pheo-Pigments: spectrophotometric equations. Limnol. Oceanogr.12, 343-346.

Madsen, J.D., Chambers, P.A.James, W.F.,Koch, E.W., Westlake, D.F., 2001. The interaction between water movement, sediment dynamics and submersed macrophytes. Hydrobiologia. $444,71-84$

Mahaney, W.M., Wardrop, D.H., Brooks, R.P., 2004. Impacts of sedimentation and nitrogen enrichment on wetland plant community development. Plant Ecol. 175, 227-243.

Moss, B., 2007. Shallow lakes, the water framework directive and life. What should it all be about?. Hydrobiologia. 584, 381-394.

Penning,W.E., Mjelde, M.,Dudley, B.,Hellsten, S.,Hanganu, J.,Kolada, A.,van den Berg, M., Poikane, S., Phillips, G., Willby, N., Ecke, F., 2008a. Classifying aquatic macrophytes as indicators of eutrophication in European lakes. Aquat.Ecol. 42, 237-251.

Penning,W.E., Dudley, B.,Mjelde, M.,Hellsten,S., Hanganu,J., Kolada,A., van den Berg, M., Poikane, S., Phillips, G., Willby, N., Ecke, F., 2008b. Using aquatic macrophyte community indices to define the ecological status of European lakes. Aquat.Ecol. 42, 253-264.

Radomski, P., Goeman, T.J., 2001. Consequences of human lakeshore development on emergent and floating-leaf vegetation abundance. N.Am.J.Fish.Manage. 21, 46-61.

Sand-Jensen, K., Pedersen, N. L., Thorsgaard, I., Moeslund, B., Borum, J., Brodersen, K. P., 2008. 100 years of vegetation decline and recovery in Lake Fure, Denmark. J. Ecol. 96, 260-271.

Sass, L.L., Bozek, M.A., Hauxwell, J.A., Wagner, K., Knight, S., 2010. Response of aquatic macrophytes to human land use perturbations in the watersheds of Wisconsin lakes, U.S.A. 
Aquat Bot. 93, 1-8.

Scheffer, M., 1998. Ecology of shallow lakes. Chapman and Hall, London, UK.

Schneider, S., 2007. Macrophyte trophic indicator values from a European perspective. Limnologica. 37, 281-289.

Søndergaard, M., Phillips, G., Hellsten, S., Kolada, A., Ecke, F., Mäemets, H., Mjelde, M., Azzella, M.M., Oggioni, A., 2013. Maximum growing depth of submerged macrophytes in European lakes. Hydrobiologia. 704, 165-177.

Søndergaard, M., Johansson, L.S., Lauridsen, T.L.,Jørgensen, T.B., Liboriussen, L., Jeppesen, E., 2010. Submerged macrophytes as indicators of the ecological quality of lakes. Freshwater Biol. 55, 893-908.

Squires, M.M., Lesack, L.F.W., Huebert, D., 2002. The influence of water transparency on the distribution and abundance of macrophytes among lakes of the Mackenzie Delta, Western Canadian Arctic. Freshwater. Biol. 47, 2123-2135.

Stelzer, D., Schneider, S., Melzer, A., 2005. Macrophyte-based assessment of lakes - a contribution to the implementation of the European Water Framework Directive in Germany. Int. Rev. Hydrobiol. 90, 223-237.

Tian, Y. M., Zhang, Y. K., Zhang, X. S., 1995. Aquatic vegetation in Lake Baiyangdian. Journal of Hebei University. 15, 59-66. (in Chinese).

Wang, H.Z., Wang, H.J., Liang, X.M., Ni, L.Y., Liu, X.Q., Cui, Y.D., 2005. Empirical modelling of submersed macrophytes in Yangtze lakes. Ecol. Model. 188, 483-491.

Williams, P., Whitfield, M., Biggs, J., Bray, S., Fox, G., Nicolet, P., Sear, D., 2004. Comparative biodiversity of rivers, streams, ditches and ponds in an agricultural landscape in Southern England. Biol. Conserv. 115, 329-341. 


\section{Caption of Figures}

Fig.1 Study area within Baoding City, China (a), and location of the study ponds (b).

Fig.2 Spatial distribution of $\mathrm{TP}(\mathrm{a})$ and $\mathrm{Z}_{\mathrm{SD}} / \mathrm{Z}_{\mathrm{M}}(\mathrm{b})$ in study area.

Fig.3 Response of TP $(a, b)$ and $Z_{S D} / Z_{M}(c, d)$ to spatial variables. Spatial variables of ponds were represented by standardized values of longitude and altitude coordinates of each pond center, respectively.

Fig.4 Response of total species richness $(\mathrm{a}, \mathrm{b})$ and submerged richness $(\mathrm{c}, \mathrm{d})$ to $\mathrm{TP}$ and $\mathrm{Z}_{\mathrm{SD}} / \mathrm{Z}_{\mathrm{M}}$.

Fig.5 Response of Shannon-Weiner diversity index $H(\mathrm{a}, \mathrm{b})$ and evenness index $J(\mathrm{c}, \mathrm{d})$ to $\mathrm{TP}$ and $\mathrm{Z}_{\mathrm{SD}} / \mathrm{Z}_{\mathrm{M}}$.

Fig.6 Response of RA sub/eme (a, b) and $\mathrm{RA}_{\text {sen/tol }}(\mathrm{c}, \mathrm{d})$ to $\mathrm{TP}$ and $\mathrm{Z}_{\mathrm{SD}} / \mathrm{Z}_{\mathrm{M}}$.

Fig.7 Response of total coverage (a, b) and biomass (c, d) to TP and $\mathrm{Z}_{\mathrm{SD}} / \mathrm{Z}_{\mathrm{M}}$.

Fig.8 The mean and range of macrophyte indicators values along TP gradient. 


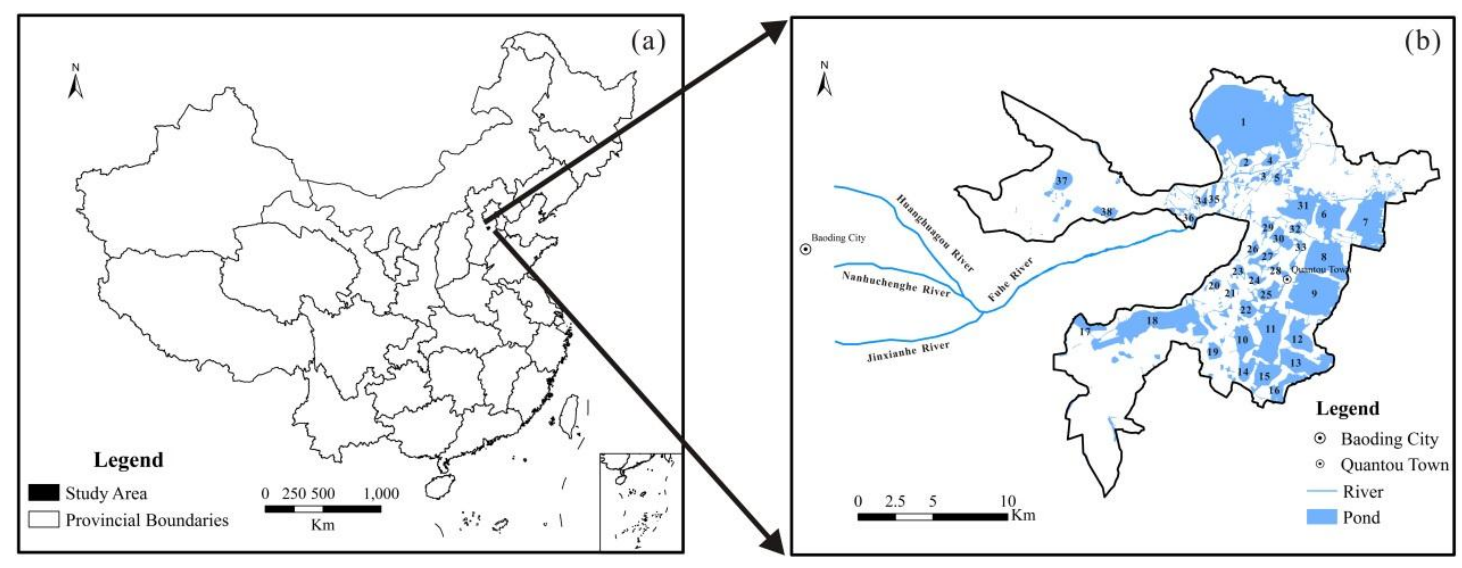

Fig.1 Study area within Baoding City, China (a), and location of the study ponds (b). Name of the study ponds:1-Shaochedian, 2-Chenjiadian, 3-Heyedian, 4-Gaojiabai zi, 5-Xiwazi, 6-Siwangdian, 7-Wanggangdian, 8-Chiyudian, 9-Pingyangdian, 10Qiantang, 11-Houtang, 12-Fanyudian, 13-Julongdian, 14-Wanloudian, 15-Huangdi an, 16-Mengjiadian, 17-Yangjiaodian, 18-Xiaobaiyangdian, 19-Sanjiaodian, 20-Du jiadian, 21-Xidian, 22-Shihoudian, 23-Badadian, 24-Xiaomaidian, 25-Damaidian, 26-Maidian, 27-Laowangdian, 28-Beihedian, 29-Yuedian, 30-Longwangdian, 31-H eledian, 32-Qiantoudian, 33-Tangjiadian, 34-Xiaoyajuan, 35-Dayajuan, 36-Nanliuz huang, 37-Zaozuodian, 38-Dabaidian. 

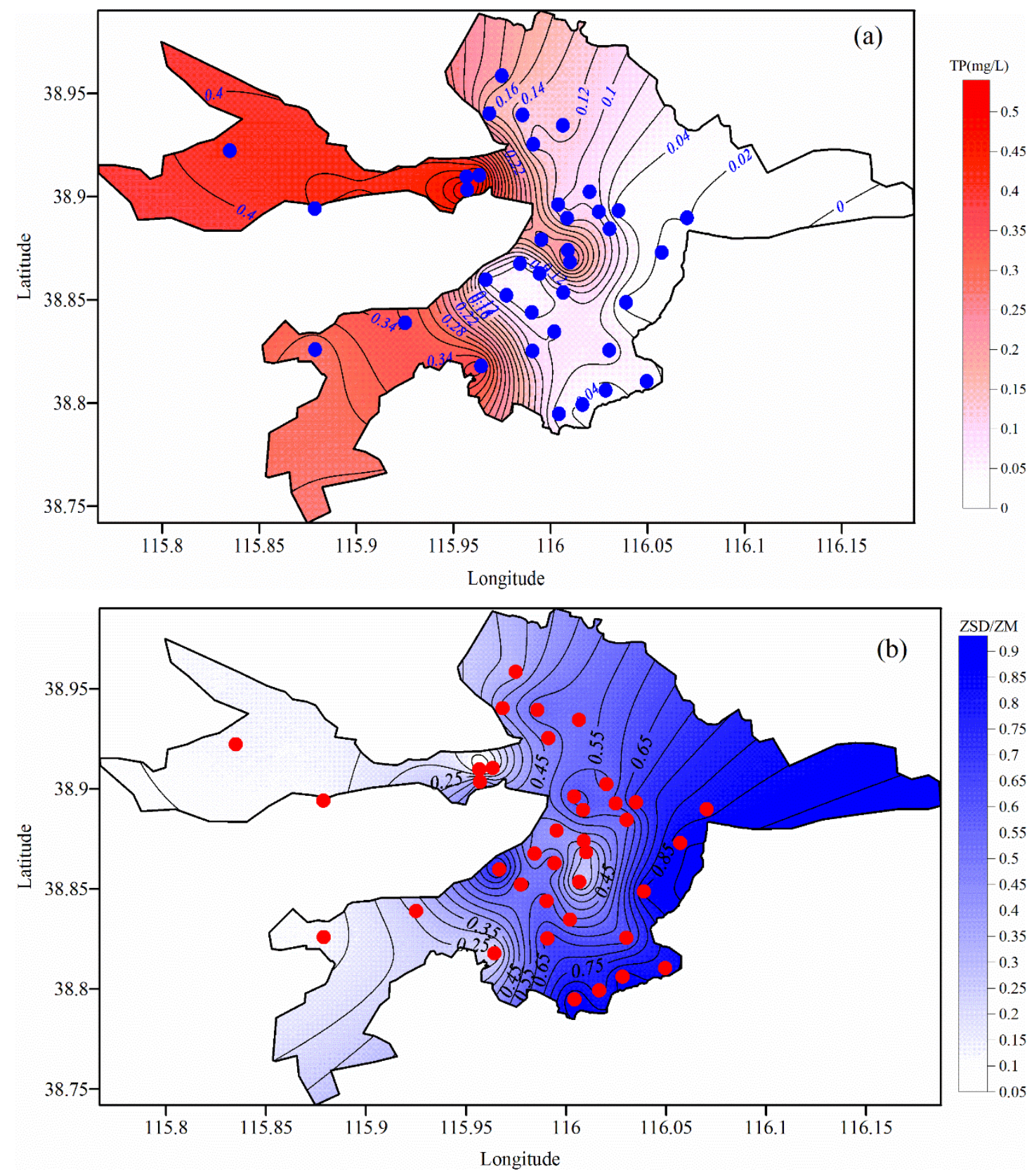

Fig.2 Spatial distribution of $\mathrm{TP}(\mathrm{a})$ and $\mathrm{Z}_{\mathrm{SD}} / \mathrm{Z}_{\mathrm{M}}$ (b) in study area. 

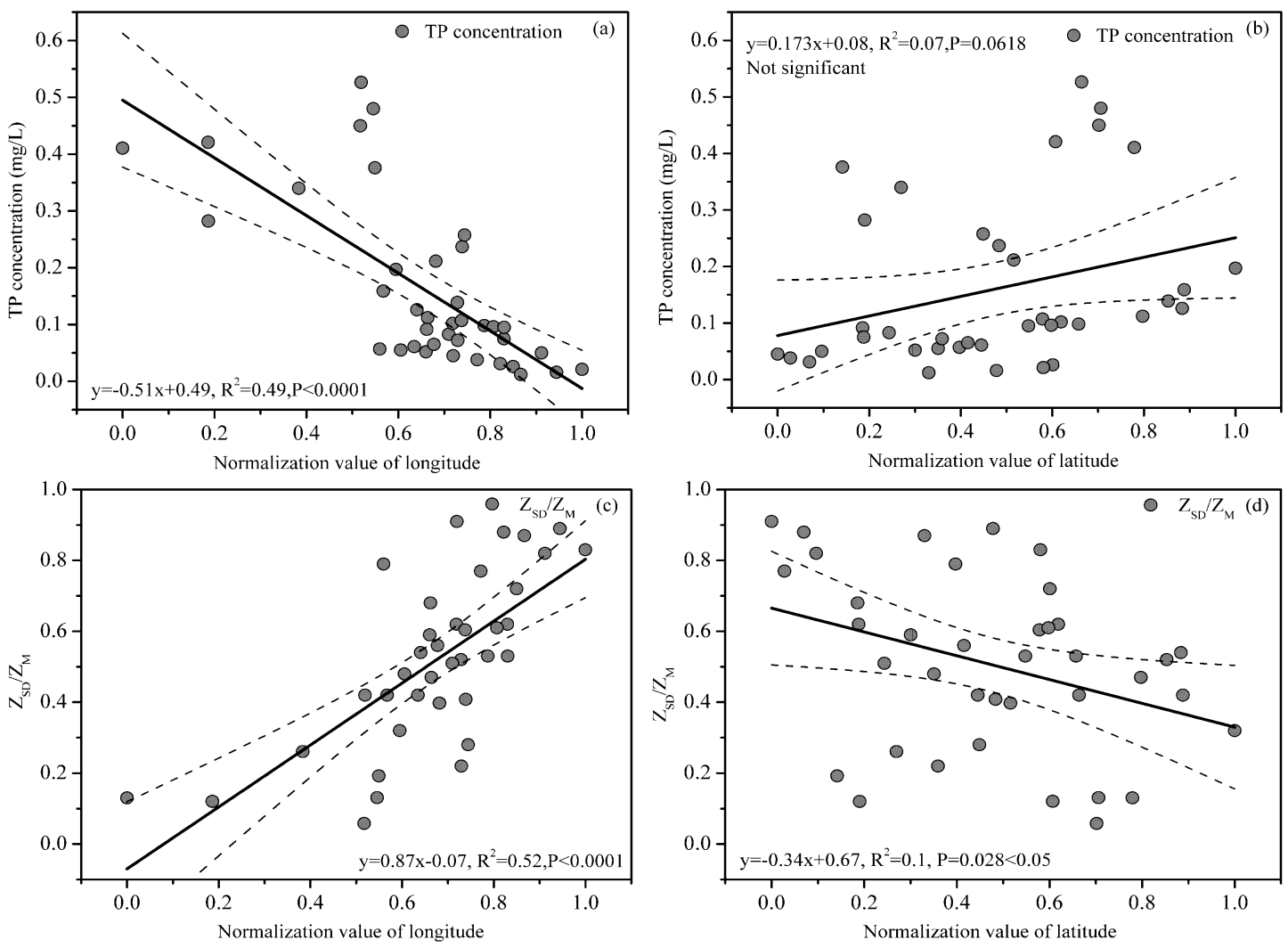

Fig.3 Response of $\mathrm{TP}(\mathrm{a}, \mathrm{b})$ and $\mathrm{Z}_{\mathrm{SD}} / \mathrm{Z}_{\mathrm{M}}(\mathrm{c}, \mathrm{d})$ to spatial variables. Spatial variables of ponds were represented by standardized values of longitude and altitude coordinates of each pond center, respectively. 

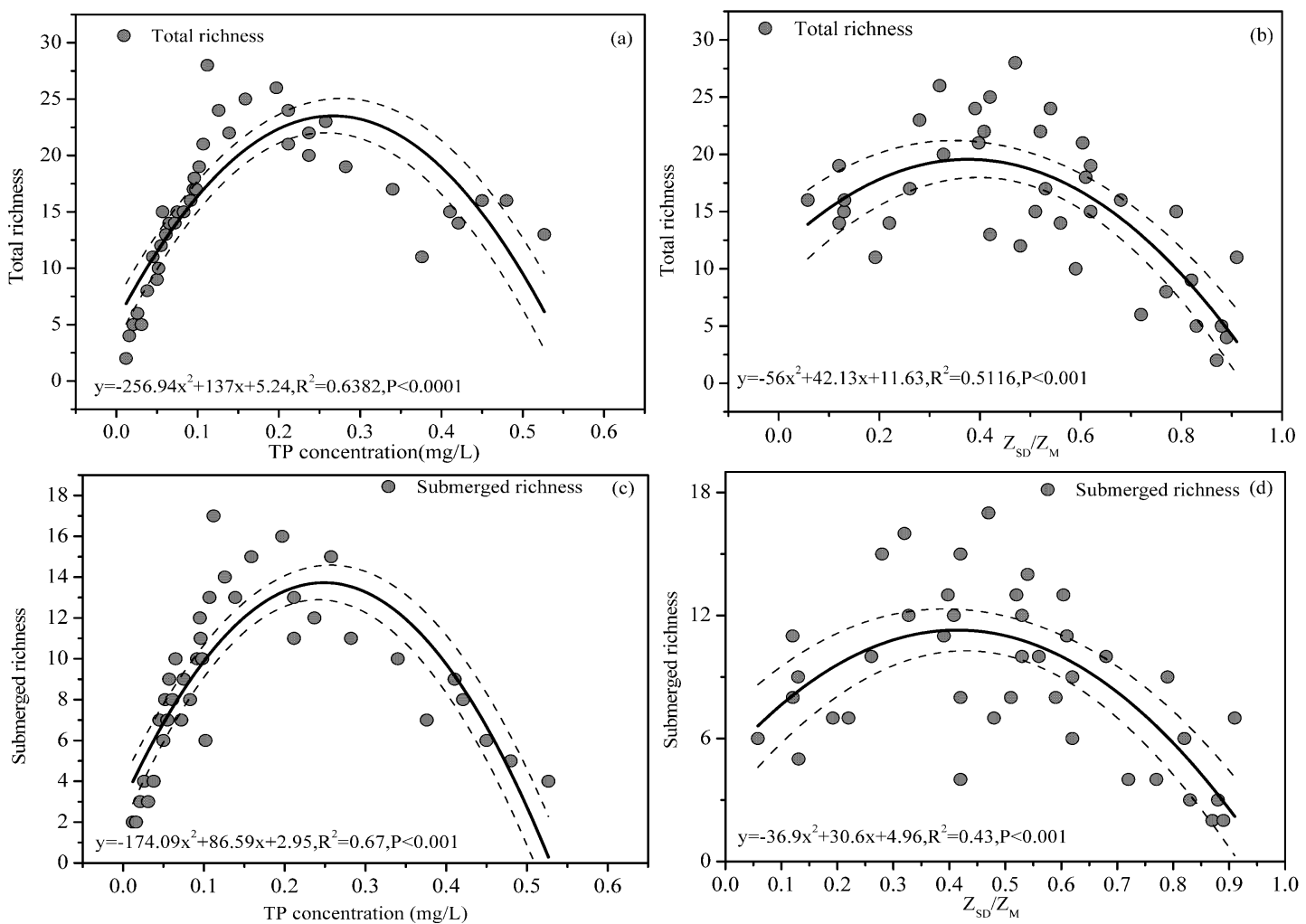

Fig.4 Response of total species richness $(\mathrm{a}, \mathrm{b})$ and submerged richness $(\mathrm{c}, \mathrm{d})$ to $\mathrm{TP}$ and $\mathrm{Z}_{\mathrm{SD}} / \mathrm{Z}_{\mathrm{M}}$. 

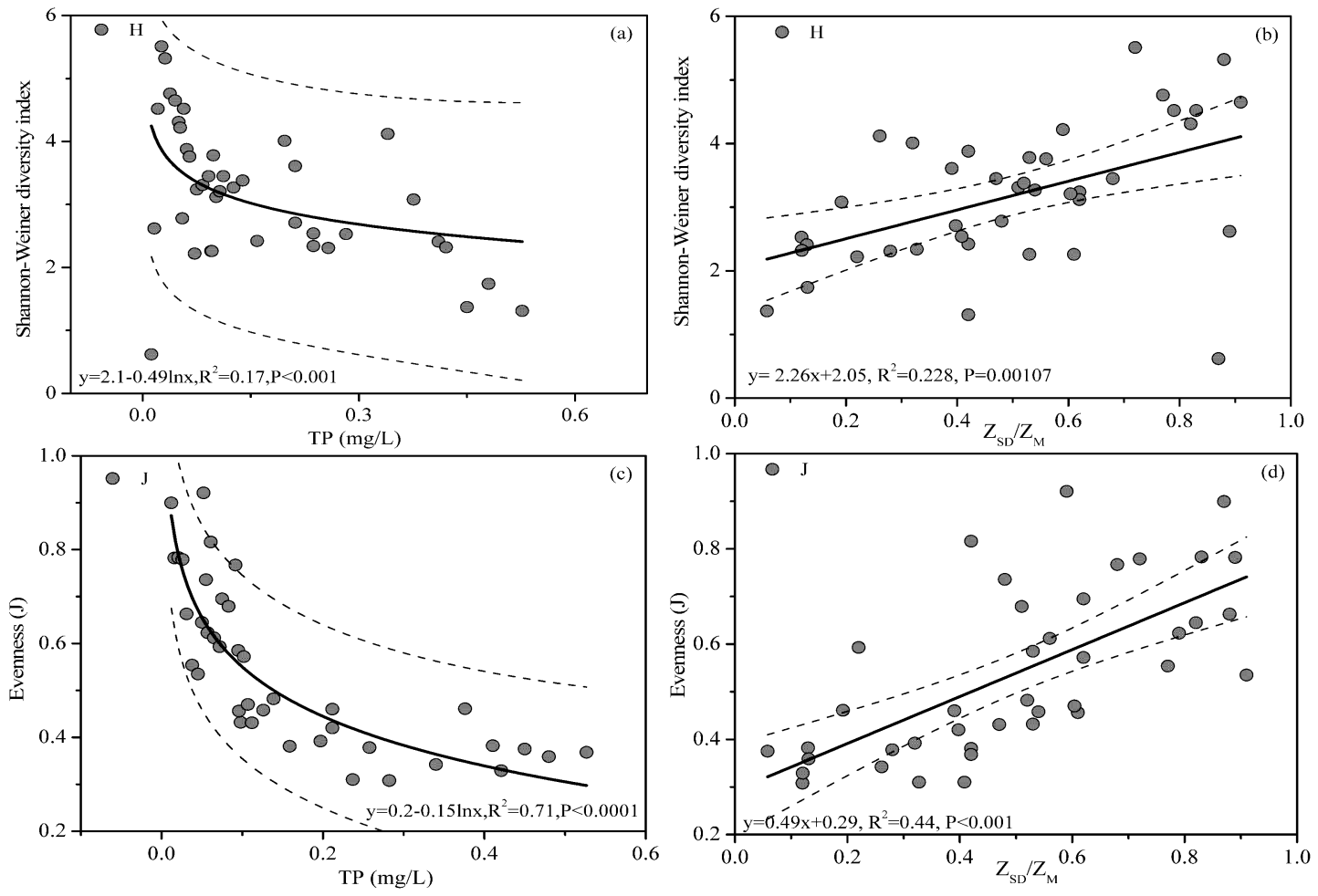

Fig.5 Response of Shannon-Weiner diversity index $H(\mathrm{a}, \mathrm{b})$ and evenness index $J(\mathrm{c}, \mathrm{d})$ to $\mathrm{TP}$ and $\mathrm{Z}_{\mathrm{SD}} / \mathrm{Z}_{\mathrm{M}}$. 

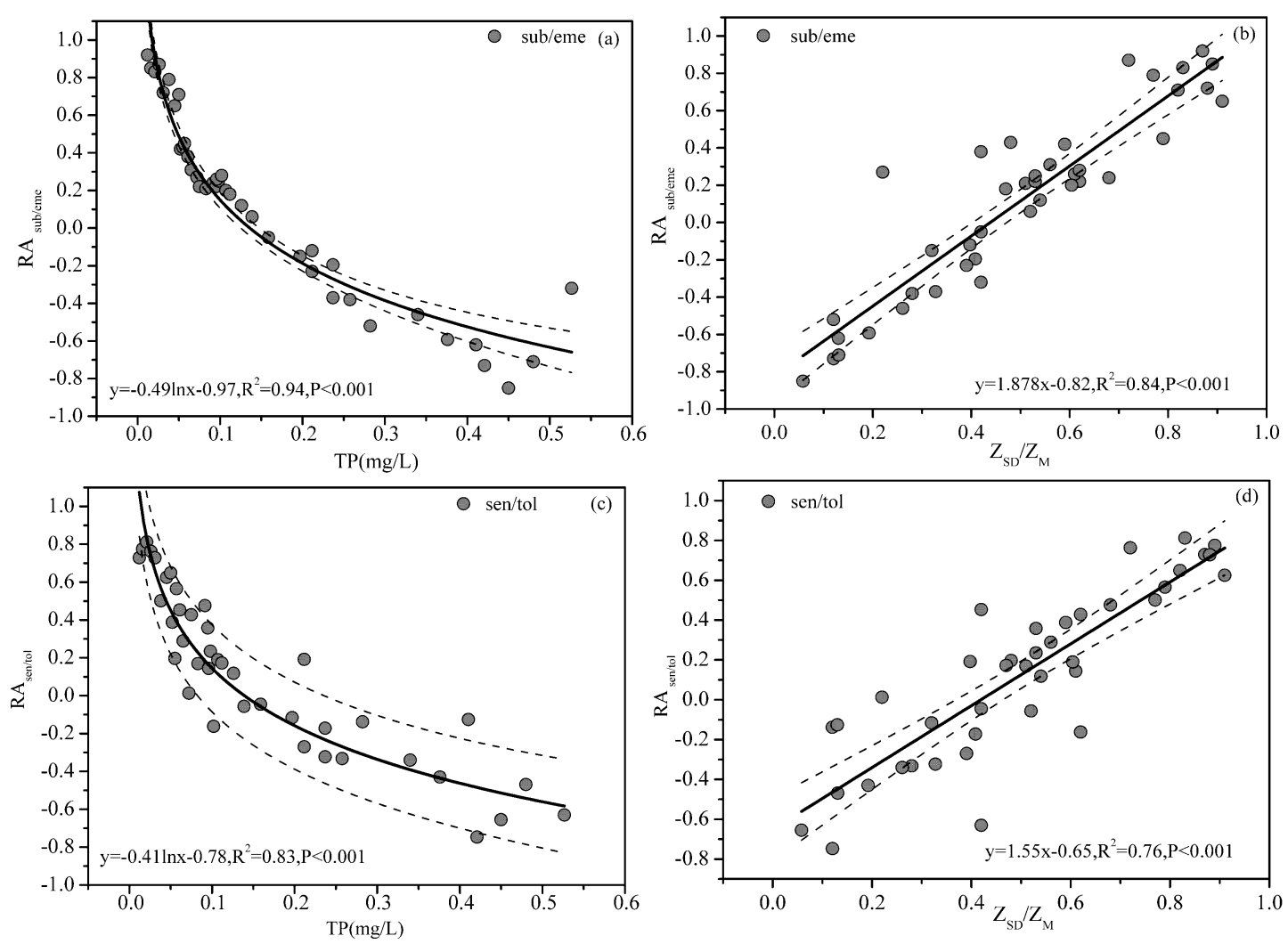

Fig.6 Response of RA sub/eme (a, b) and $\mathrm{RA}_{\text {sen/tol }}(\mathrm{c}, \mathrm{d})$ to $\mathrm{TP}$ and $\mathrm{Z}_{\mathrm{SD}} / \mathrm{Z}_{\mathrm{M}}$. 

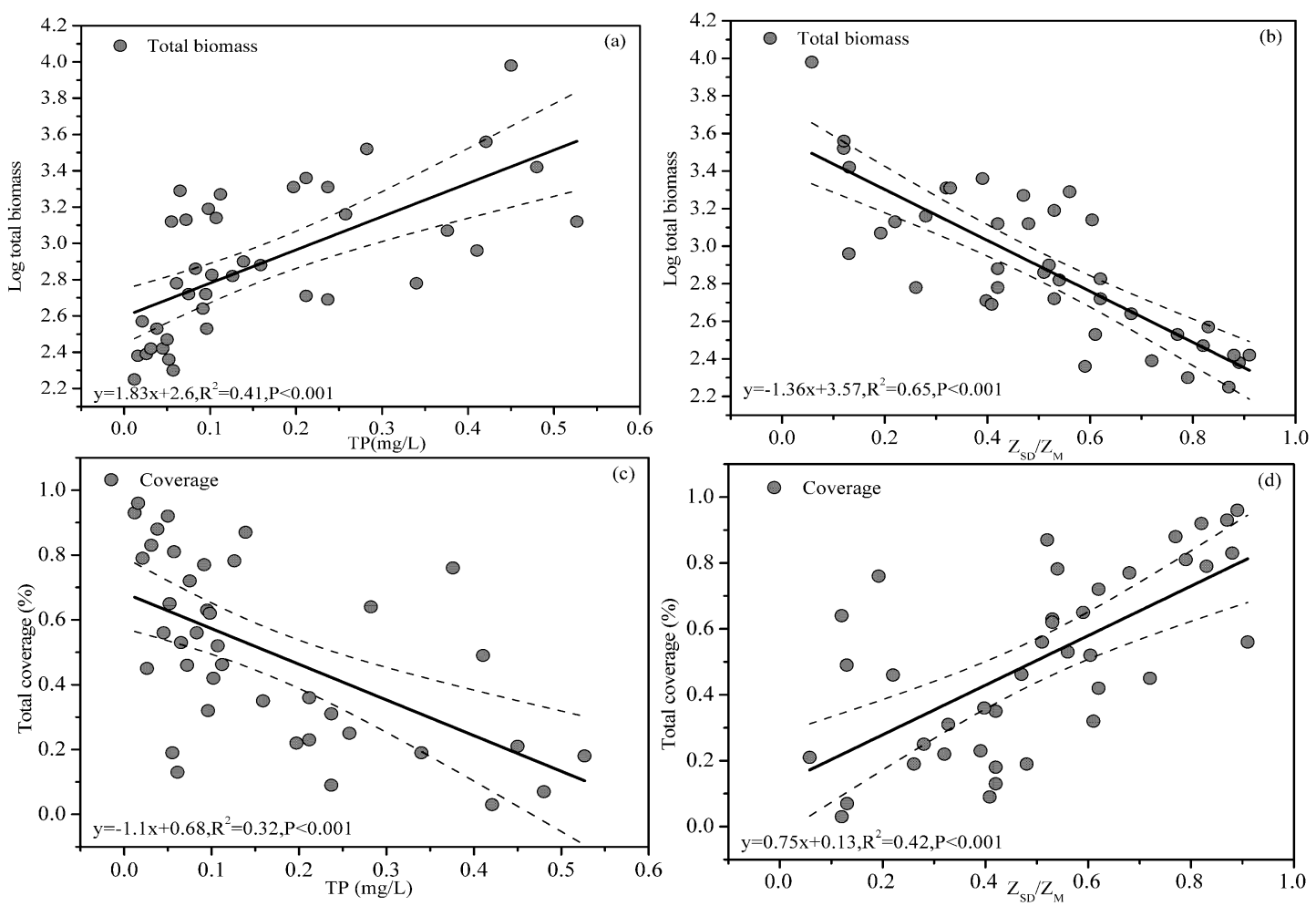

Fig.7 Response of total biomass ( $a, b)$ and total coverage (c, d) to TP and $\mathrm{Z}_{\mathrm{SD}} / \mathrm{Z}_{\mathrm{M}}$. 

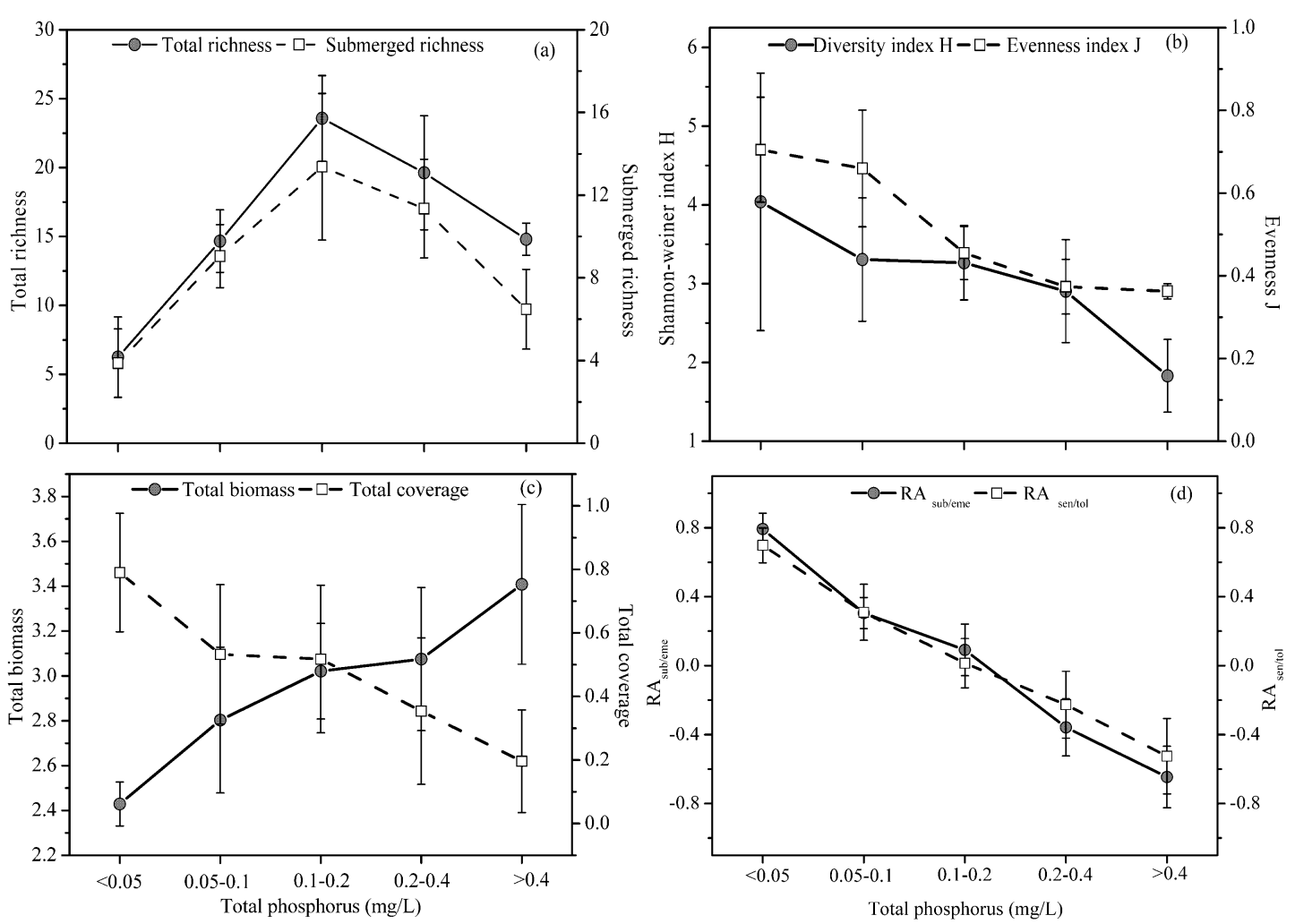

Fig.8 The mean and range of macrophyte indicators values along TP gradient. 


\section{Caption of Tables}

Table.1 Mean, standard deviation (s.d.) and range for variables characterizing the pond physico-chemical status ( $n=38)$.

Table. 2 Pearson correlation coefficients $r$ between environmental variables.

Table.3 Pearson correlation coefficients $r$ describing the relationships between macrophyte indicators and eutrophication pressure indicators.

Table.4 Numerical intervals and scores of the four macrophyte indicators.

Table.5 Total scores and distributions of study ponds within each status category. 
Table.1 Mean, standard deviation (s.d.) and range for variables characterizing the pond physico-chemical status $(n=38)$.

\begin{tabular}{lll}
\hline \multicolumn{1}{c}{ Variable } & Mean \pm SD & Range \\
\hline Surface area (hectares) & $65 \pm 4.6$ & $23-172$ \\
Mean depth $(\mathrm{m})$ & $1.21 \pm 0.35$ & $0.72-1.53$ \\
$\mathrm{pH}$ & $8.24 \pm 0.18$ & $7.38-8.39$ \\
Dissolved oxygen(mg/L) & $3.39 \pm 1.03$ & $3.21-12.6$ \\
Conductivity(us/cm) & $480 \pm 231$ & $45-1187$ \\
Total nitrogen(mg/L) & $5.78 \pm 7.78$ & $0.96-21.7$ \\
Total phosphorus(mg/L) & $0.16 \pm 0.14$ & $0.012-0.5266$ \\
Transparency (cm) & $76 \pm 15$ & $37-146$ \\
Chlorophyll a (ug/L) & $35 \pm 58$ & $4.21-169.3$ \\
Suspend solids(mg/L) & $17.4 \pm 10.5$ & $5.7-135$ \\
\hline
\end{tabular}


Table.2 Pearson correlation coefficients $r$ between environmental variables.

\begin{tabular}{|c|c|c|c|c|c|c|c|c|c|c|c|}
\hline Variables & $\mathrm{Z}_{\mathrm{M}}$ & $\mathrm{Z}_{\mathrm{SD}}$ & $\mathrm{Z}_{\mathrm{sD}} / \mathrm{Z}_{\mathrm{M}}$ & Area & Tem & Cond & $\mathrm{pH}$ & $\mathrm{NH}_{3}-\mathrm{N}$ & TN & TP & Chl-a \\
\hline$Z_{M}$ & 1 & $0.62^{* *}$ & -0.21 & $0.33^{* *}$ & $0.84^{* *}$ & -0.12 & 0.02 & -0.2 & $0.69 * * *$ & $-0.71 * * *$ & -0.11 \\
\hline$Z_{S D}$ & & 1 & $0.72 * *$ & 0.06 & 0.27 & -0.09 & 0.24 & $-0.63^{* *}$ & 0.21 & $-0.54 * *$ & $-0.75^{* * *}$ \\
\hline $\mathrm{Z}_{\mathrm{SD}} / \mathrm{Z}_{\mathrm{M}}$ & & & 1 & 0.03 & 0.2 & 0.32 & $0.35^{*}$ & $-0.57^{* *}$ & -0.19 & $-0.56 * *$ & $-0.42^{* *}$ \\
\hline Area & & & & & 0.02 & 0.03 & 0.01 & 0.02 & 0.01 & 0.03 & 0.01 \\
\hline Tem & & & & & 1 & -0.25 & 0.14 & -0.31 & $0.67^{* * *}$ & $-0.54^{*}$ & -0.28 \\
\hline Cond & & & & & & 1 & 0.04 & -0.15 & -0.36 & 0.05 & -0.24 \\
\hline $\mathrm{pH}$ & & & & & & & 1 & -0.19 & -0.22 & $-0.61 *$ & $-0.47 *$ \\
\hline $\mathrm{NH}_{3}-\mathrm{N}$ & & & & & & & & 1 & 0.08 & $0.63 * *$ & $0.55^{* *}$ \\
\hline TN & & & & & & & & & 1 & -0.17 & 0.12 \\
\hline TP & & & & & & & & & & 1 & $0.58^{* *}$ \\
\hline Chl-a & & & & & & & & & & & 1 \\
\hline
\end{tabular}

$Z_{M}$ : mean water depth, $m ; Z_{S D}$ : Secchi depth, $m ; Z_{S D} / Z_{M}$ : ratio between Secchi depth and mean water depth; Tem: water temperature; Cond: conductivity, $\mathrm{mS} / \mathrm{cm}$; $\mathrm{NH}_{3}-\mathrm{N}$ : ammonia nitrogen, $\mathrm{mg} / \mathrm{L} ; \mathrm{TN}$ : total nitrogen $\mathrm{mg} / \mathrm{L}$; TP: total phosphorous mg/L; Chla: phytoplankton chlorophyll a, ug/L. ${ }^{*} P<0.05$; $^{*} P<0.01$; ${ }^{* *} \mathrm{P}<0.001$. 
Table.3 Pearson correlation coefficients $r$ describing the relationships between macrophyte indicators and eutrophication pressure indicators.

\begin{tabular}{|c|c|c|c|c|}
\hline \multirow{2}{*}{ Macrophyte indicators } & \multicolumn{2}{|c|}{ TP } & \multicolumn{2}{|c|}{$\mathrm{Z}_{\mathrm{SD}} / \mathrm{Z}_{\mathrm{M}}$} \\
\hline & $\mathrm{R}$ & $P$ & $\mathrm{R}$ & $P$ \\
\hline \multicolumn{5}{|l|}{ Richness } \\
\hline Total & 0.303 & 0.057 & 0.37 & $<0.05$ \\
\hline Submerged & 0.104 & 0.524 & 0.45 & $<0.01$ \\
\hline Floating-leaved & 0.033 & 0.78 & 0.012 & 0.98 \\
\hline Emergent & 0.032 & 0.72 & 0.41 & 0.26 \\
\hline \multicolumn{5}{|l|}{ Diversity } \\
\hline H (Shannon-Weiner index) & -0.52 & $<0.001$ & 0.498 & $<0.001$ \\
\hline $\mathrm{J}$ (Eveness index) & -0.804 & $<0.001$ & 0.676 & $<0.0001$ \\
\hline \multicolumn{5}{|l|}{ Abundance } \\
\hline Biomass & 0.642 & $<0.001$ & -0.8032 & $<0.001$ \\
\hline Coverage & -0.5639 & $<0.01$ & 0.6480 & $<0.01$ \\
\hline \multicolumn{5}{|l|}{ Community structure } \\
\hline $\mathrm{RA}_{\text {sub/eme }}$ & -0.91 & $<0.001$ & 0.9206 & $<0.001$ \\
\hline $\mathrm{RA}_{\text {sen/tol }}$ & -0.88 & $<0.001$ & 0.87 & $<0.001$ \\
\hline
\end{tabular}


Table.4 Numerical intervals and scores of the four macrophyte indicators.

\begin{tabular}{cccccc}
\hline $\begin{array}{c}\text { TP } \\
\text { classes }\end{array}$ & \multicolumn{1}{c}{ Diversity } & Abundance & \multicolumn{2}{c}{ Community structure } & \\
$(\mathrm{mg} / \mathrm{L})$ & (evenness) & Biomass & \multicolumn{1}{c}{$\mathrm{RA}_{\text {sub/eme }}$} & \multicolumn{1}{c}{$\mathrm{RA}_{\text {sen/tol }}$} & Score \\
\hline $0-0.05$ & $0.69-0.77$ & $2.43-2.54$ & $0.34-0.82$ & $0.27-0.69$ & 1 \\
$0.05-0.1$ & $0.48-0.69$ & $2.54-2.75$ & $0.07-0.34$ & $-0.12-0.27$ & 2 \\
$0.1-0.2$ & $0.44-0.48$ & $2.75-2.89$ & $-0.36-0.07$ & $-0.14-(-0.12)$ & 3 \\
$0.2-0.4$ & $0.38-0.44$ & $2.89-3.07$ & $-0.47-(-0.36)$ & $-0.38-(-0.14)$ & 4 \\
$0.4-0.6$ & $<0.38$ & $>3.07$ & $<-0.47$ & $<-0.38$ & 5 \\
\hline
\end{tabular}


Table.5 Total scores and distributions of study ponds within each status category.

\begin{tabular}{llllll}
\hline Status categories & $\mathrm{I}$ & II & III & IV & V \\
\hline Total scores & $<4$ & $5-8$ & $9-12$ & $13-16$ & $17-20$ \\
Serial number of study & $6,7,8,9,13,14,15$ & $10,11,12,20,21,22,23,24,25$, & & & \\
ponds & 16 & $31,32,33$ & $1,2,3,4,5,29,30$ & $17,18,19,26,27$ & $34,35,36,37$ \\
& & & &, 28, &, 38 \\
\hline
\end{tabular}

